\title{
SCENA SAKRAMENTU POKUTY W KORONIE DRZEWA SAKRAMENTÓW W JASIONEJ
}

W kościele parafialnym p.w. Marii Magdaleny w Jasionej na łuku tẹczowym od strony dawnego chóru (obecnie w kaplicy bocznej kościoła) na przełomic XV i XVI w. namalowana została scena ukazująca drzewo rajskie i drzewo sakramentów ${ }^{1}$. W dolnej części korony drzewa sakramentów w medalionie przedstawiono sakrament pokuty. Kapłan w postawie siedzącej, pochylony nieco do przodu w stronę klęczącego przed nim penitenta i penitent wychylony ku niemu do przodu, szepczący mu grzechy do prawego ucha, jeszcze reprezentuja motyw ikonografíczny pojawiający się w obrazach gotyckich Średniowiecza (il. 1) ${ }^{2}$.

Ks. A. Nowowiejski w podręczniku „Wykład liturgii Kościoła katolickiego" przypomina najstarsza tradycje zwyczaju liturgicznego sakramentu pokuty oraz miejsca kapłana i penitenta w czasie spowiedzi. Z wielu tekstów Ojców Kościoła a Tertuliana w szczególności wiadomo, że wierni klękali przed kapłanem dla odbycia spowiedzi, kaplani zaś mogli siedzieć. Św. Hieronim pisze, że „locus accomodatus pro poenitentia et confessione est templum et altare", zaś św. Cyprian podaje, iż spowiedź odbywała się przy kratkach prezbiterium. Ale od VIII w. spowiadający się siadal przy kapłanie na osobnym

${ }^{1}$ I. Błaszczyk, Funkcje ideowe motywu drzewa w polskiej sztuce gotyckiej.W: Poznańskie Towarzystwo Przyjaciól Nauk. Sprawozdania nr 99 za 1981. Wydzial Nauk o sztuce. Poznań 1983, s. 32; A. Karłowska-Kamzowa, Ślqsk. W: Gotyckie malarstwo ścienne w Polsce. Poznań 1984, s. 100, il. 128.

${ }^{2}$ Tego rodzaju motyw nie jest ostatnim przykładem, który pojawił się na terenie Polski, gdyż także w Hortus Animae Martina Scharffenberga, wydanego w Krakowie w 1533 roku (Biblioteka Kurnicka Polskiej Akademii Nauk, Cim. Q 103) znajduje się rycina ukazująca spowiednika siedzącego na tronie i penitenta klęczącego z jego lewej strony, szepczącego mu grzechy do ucha (il. 2). - Dziękuję Pani prof. A. Karłowskiej-Kamzowej za wskazanie mi starodruku. 


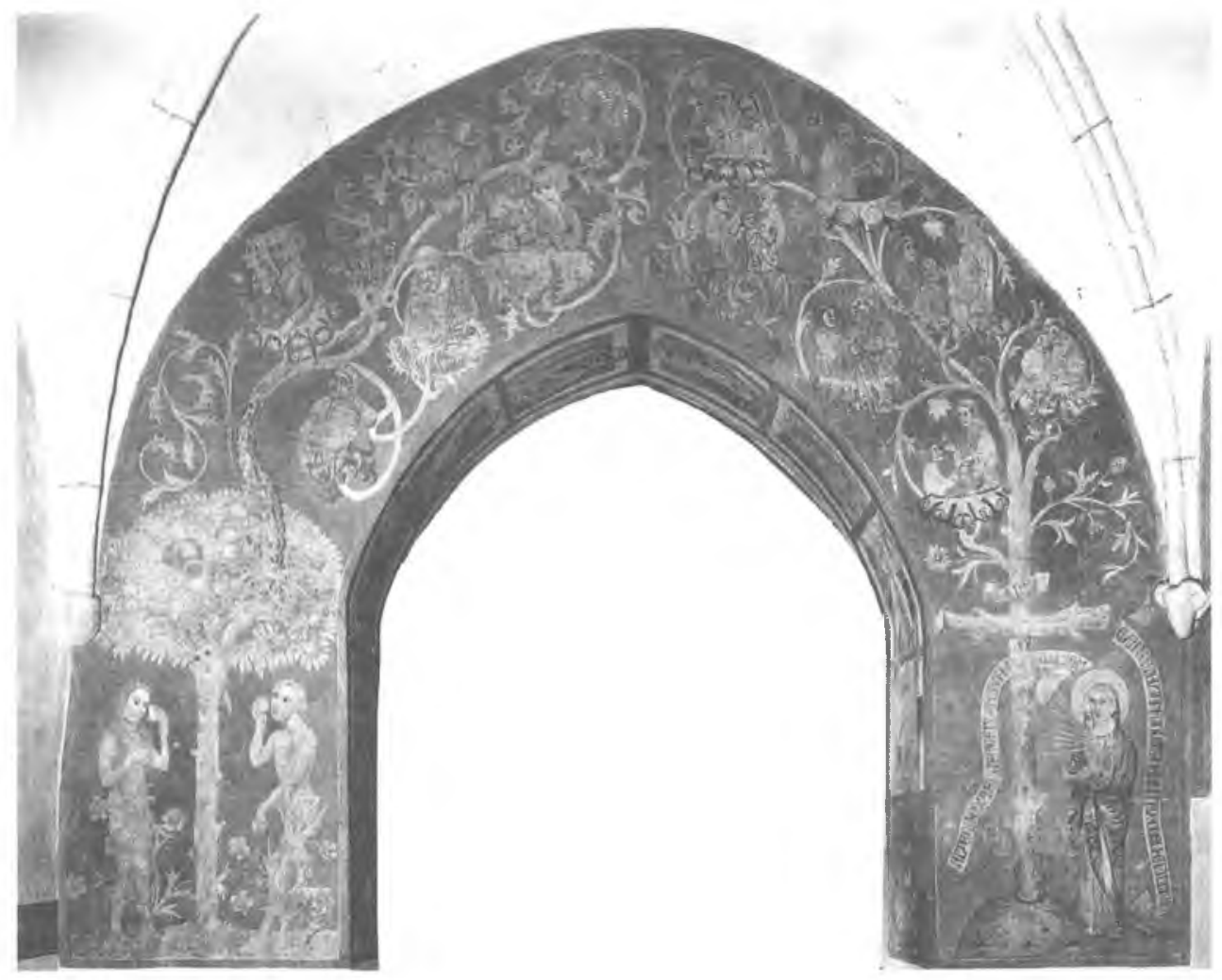

Il. 1. 
miejscu, na co wskazują zarządzenia rzymskie i pisarze od VIII do XI w. W traktacie przypisywanym Alkuinowi zostało odnotowane: „Deinde jubeat cum sacerdos sedere contra se". Spowiedź miała miejsce także w przedsionku, w drzwiach lub pobliskich zabudowaniach kościoła. Okolo XI w. między innymi w Normandii, Anglii i Irlandii w murze chóru czyniono otwór okienny, do którego wewnatrz kościoła przylegało siedzenie spowiednika. Penitent podchodził do spowiedzi i stawał przed oknem od zewnętrznej strony światyni. Niekiedy spowiednik siadywał $\mathrm{w}$ niszy ściennej a na zewnątrz kościoła dla penitenta sporządzony byl rodzaj przedsionka ${ }^{3}$.

W okresie gotyckim kapłan w czasie spowiedzi siedział w stalli chóru, na krześle z poręczami często z zapleckiem, a penitent klękal przed nim, aby wyznać grzechy i otrzymać rozgrzeszenie. W taki sposób, w postawie klęczącej, wyobrażony został starszy człowick, któremu kapłan - dominikanin, siedzący na tronie z pięknym zapleckiem zakończonym szczytem, kładzie rękę na głowie w chwili rozgrzeszenia, na fresku ukazującym Via Veritatis (zarazem Kościół walczący), z lat 1366-1368, Andrea Bonaiuti, w kaplicy hiszpańskiej w kościele Santa Maria Novella we Florencji ${ }^{4}$. Podobnie przedstawil tę scenę Andrea Pisano na reliefie pochodzacym z campanilli Giotta we Florencji (obecnie we florenckiej Museo dell'Opera del Duomo) ${ }^{5}$. W nieco innym momencie spowiedzi, poprzedzającym rozgrzeszenie, penitenta i kaplana namalował Magister Vitae Imperatorum na miniaturze z $1422 \mathrm{r}$. w Breviario Ambrosiano (ms. M 26, fol. 84r) w Biblioteca Capitolare di S. Ambrogio w Mediolanie. Kapłan siedzi pod baldachimem tronu, nogi ma postawione na podnóżku, pochylony jest nieco do przodu, łokcie ma oparte na kolanach i słucha mężczyznę, klęczacego przed nim poniżej ${ }^{6}$. Roger van der Weyden, na Ołtarzu Siedmiu Sakramentów z lat 1452-1455 (Antwerpia, Koninklijk Museum voor Schone Kunsten), umieścił kapłana siedzącego na krześle i klęczącego przed nim penitenta, tuż przed przegrodą oddzielająca prezbiterium od nawy głównej kościoła. Spowiednik siedzi tyłem odwrócony w stronę przegrody i prezbiterium, zaś penitent dzięki temu może patrzyć na ołtarz usytuowany w głębi prezbiterium ${ }^{7}$.

${ }^{3}$ A. J. Nowowiejski, Wyklad liturgii Kościola katolickiego. T. 1. Warszawa 1893, s. $1180-1181$.

${ }^{4}$ J. Polzer, Andrea di Bonaiuto's Via Veritatris and Dominiacan Thought in Late Medieval Italy. „The Art Bulletin”, 77:1995, nr 2, s. 274, il. 1, 11; D. Norman, Siena. Florence and Padua. Art, Society and Religion 1280-1400, 2. New Haven and London 1995, s. 223 , il. 275 .

${ }^{5}$ J. Polzer, Andrea di Bonaiuto's via..., op. cit., s. 274, il. 17.

${ }^{6}$ A. Ricagni, Contributo alla storia della miniatura lombarda, manoscritti datati del' 300 e del primo' 400. „Arte Cristiana”, 79:1991, Settembre-Ottobre, s. 344-345, il. 11. •

${ }^{7}$ E. Panofsky, Early Netherlandish Painting. New York 1971, s. 299, il. 349. 
Wydaje się, że tradycja klękania przed sicdzącym spowiednikiem, czy miejsca spowiedzi w kościele niedaleko oltarza, zawarta w wypowiedziach Ojców Kościoła przetrwała do czasów Średniowiecza. Tym bardziej, że umieszczenie w takim miejscu krzesła spowiednika jak na ołtarzu Rogera van der Weydena jest zgodne z wypowiedzią wspomnianego ks. A. Nowowiejskiego, który podaje, że siedzenia nie miały nigdy stałego miejsca $w$ kościele, ale w średniowiecznych rozporządzeniach pokutnych nader często jest mowa o wyznawaniu grzechów ante altare, stąd krzesla musiaky się znajdować w pobliżu oltarza, lub tak być położone, aby od nich można było widzieć ołtarz i one same łącznie $z$ księdzem i penitentem mogły być dostrzeżone przez wszystkich zgromadzonych w kościele. Siedzenia zabroniono stawiać za oltarzem lub w zakrystii ${ }^{8}$.

Wszystkie reliefy angielskie wymienione przez Ann Eljenholm Nichols ${ }^{9}$ przedstawiaja, jak według wyżej wymienionych wzorów, penitenta klęczacego i spowiednika siedzacego na krześle, w ławce lub na czymś w rodzaju tronu. Przy czym postać klęcząca na wprost siedzącego kapłana może być zwyczajem wschodnio angielskim. W Brook i Alderford (Norfolk) kapłan trzyma ręce penitenta w swoich, w geście, który według rytuału liturgicznego związany jest $z$ wypowiedzeniem trzy razy słów przez spowiadającego się: „In manus tuas Domine, commendo spiritum mcum". Kiedy kaplan pochyla się do penitenta a ten do niego, ukazany jest moment wyznawania grzechów, zaś gdy spowiednik unosi ręce, aby polożyć je na głowie penitenta, lub trzyma ręce na jego glowie, jak to jest wyobrażone na jednej trzeciej reliefów angielskich, oznacza to, że wypowiada słowa rozgrzeszenia ${ }^{10}$.

$\mathrm{Na}$ temat tronu, zasiadania na tronie, a stąd i określonej tym miejscem funkcji i władzy napisano wiele $^{11}$. Zasiadanie na tronie ma swoje źródło w Starym i Nowym Testamencie a w tym ostatnim związane jest z Chrystusem, Arcykapłanem, któremu poświęcony jest cały list do Hebrajczyków. Wiersz pierwszy ósmego rozdziału tego listu mówi: „takiego mamy arcykaplana, który zasiadł po prawicy tronu Majestatu w niebiosach". Przedstawicnia ukazujące Chrystusa zasiadającego na tronie wyobrażają stan chwalebnego wyniesienia Chrystusa po zmartwychwstaniu ${ }^{12}$ lub Sędziego w dniu Paru-

\footnotetext{
${ }^{8}$ A. J. Nowowiejski, Wykład liturgii..., t. 1, s. 1181

${ }^{9}$ Seable Signs. The Iconography of the Seven Sacraments 1350-1544. The Boydel Press 1993, s. 222-240.

${ }^{10}$ Tamże, s. 223-228.

${ }^{11}$ Cała literatura przedmiotu zebrana jest W: H. Laag, Thron (ohne Hetoimasia); Th. v. Bogyay, Thron (Hetoimasia). W: Lexikon der christlichen Ikonographie, herausgeben von E. Kirschbaum SJ in zusamen arbeit mit G. Bandman, W. Braunfels, J. Kollwitz, W. Mrazek, A. Schmid, H. Schnell. Rom-Freiburg-Basel-Wien 1990, szp. 304-313.

${ }^{12}$ T. Dobrzeniecki, Nubijska Maiestas Domini z katedry w Faras w Muzeum Narodowym w Warszawie. „Rocznik Muzeum Narodowego w Warszawie”, 31:1987, s. 263-390.
} 
zji $^{13}$. Tron biskupi - katedra w czasach apostolskich i później wiązana byla z uczniami Chrystusa i ich następcami, o czym wspominaja Tertulian, Euzebiusz i wielu innych ${ }^{14}$. I chociaż wiadomo, żc Ojcom Kościoła w swoich wypowiedziach nie chodziło tylko o krzesła lecz także o zachowany depozyt wiary, to jednak symboliczne zasiadanie biskupa na tronie, w obrazowych przedstawieniach, jak to jest ukazane w przypadku św. Piotra zasiadajacego i czytającego zwój w reliefie na sarkofagu „Dwóch Braci” spod bazyliki Św. Pawła za Murami (obecnie Watykan, lata 330-360), zwiazane jest z funkcja apostolska jaka otrzymał od Chrystusa ${ }^{15}$. Do najbardzicj znanych tronów - katedr biskupich należą katedra $z$ pierwszej połowy VI w. biskupa Maximiana w Rawennie $^{16}$, czy katedra Św. Piotra z IX w. przywieziona do Rzymu na koronację Karola Lysego, a potem od XI w. używana do papieskich ceremonii ${ }^{17}$. W katakumbach i bazylikach po bokach biskupa zasiadali kaplani. Siedzeniom kapłańskim, niższym nieco od stolicy biskupiej i tronowi biskupa, Euzebiusz nadaje wspólną nazwę thronus. Jednakże stolica biskupa byla thronus seu sedes alta, a siedzenie kapłanów thronus seu sedes secunda. Grzegorz z Nazjanzu siedzenia kapłańskie wprost określa Secundi throni:

Primum, secundos qui tenent

Templi sacri thronos,

Plebique praesidens,

In me fuerunt haud boni.

Chociaż Atanazy stolicę biskupią nazywa thronus, a siedzenia kapłańskie subsellia ${ }^{18}$.

W tym kontekście, tronu i zwiazanej z nim władzy i pozycji, należałoby zauważyć, że podanie przez penitenta dłoni spowiadającemu go kapłanowi nawiązuje do świeckiej ceremonii homagium składanego przez vasala swemu panu. Na miniaturach w Grandes Chroniques Karola V (Paris, Bibliothèque Nationale, Ms fr. 2813, fol. 290, 357, 357v) ukazane sa sceny homagium składanego przez Henryka III przed św. Ludwikiem i Edwarda III przed Filipem de Valois. Na ostatniej z trzech miniatur Edward III przyklęka na

${ }^{13}$ R. Berger, Die Darstellung des thronenden Christus in der romanischen Kunst. Reutlingen 1926; F. van der Meer, Maiestas Domini, Théophanies. De l'Apacalypse dans l'art chretien. Roma-Paris 1938; B. Brenk, Tradition und Neuerung in der christlichen Kunst des ersten Jahrtausends. Studien zur Geschichte des Weltgerichtsbildes. Wien 1966.

${ }^{14}$ A. Nowowiejski, Wyktad liturgii..., t. 1, s. 1143.

${ }^{15}$ B. Filarska, Poczatki sztuki chrześcijańskiej. Lublin 1986, s. 164, il. 175.

${ }^{16}$ G. Bovini, La Cattedra eburnea del Vescovo Massimiano di Ravenna. Ravenna 1990, s. 12-45. - Autor podaje podstawowa literaturę przedmiotu.

${ }^{17}$ H. L. Kessler, On the State of Medieval Art History. „The Art Bulletin”, 70:1988, nr 2 , s. 175 , il. 5 .

${ }^{18}$ A. Nowowiejski, Wyklad liturgii..., t. 1, s. 1160. 
Jolio

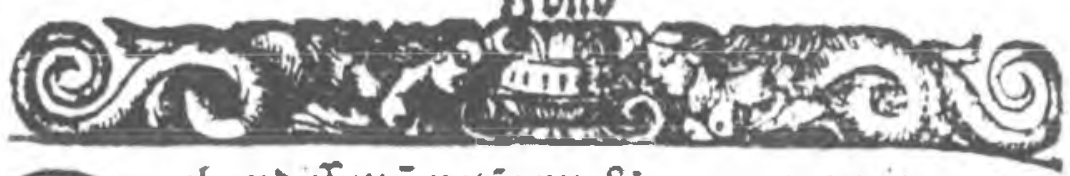

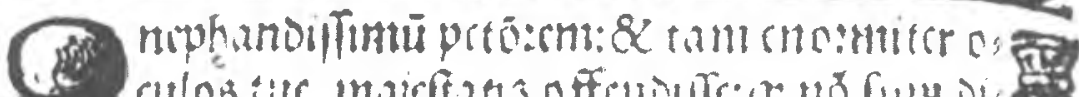

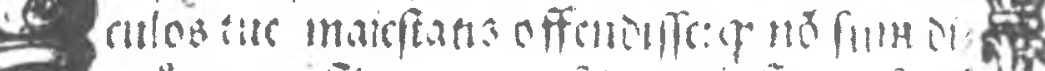

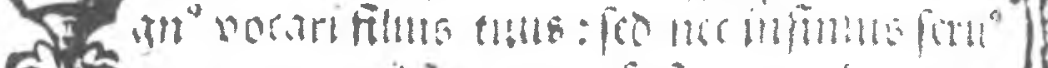

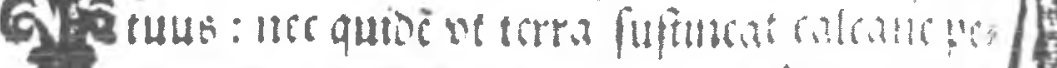

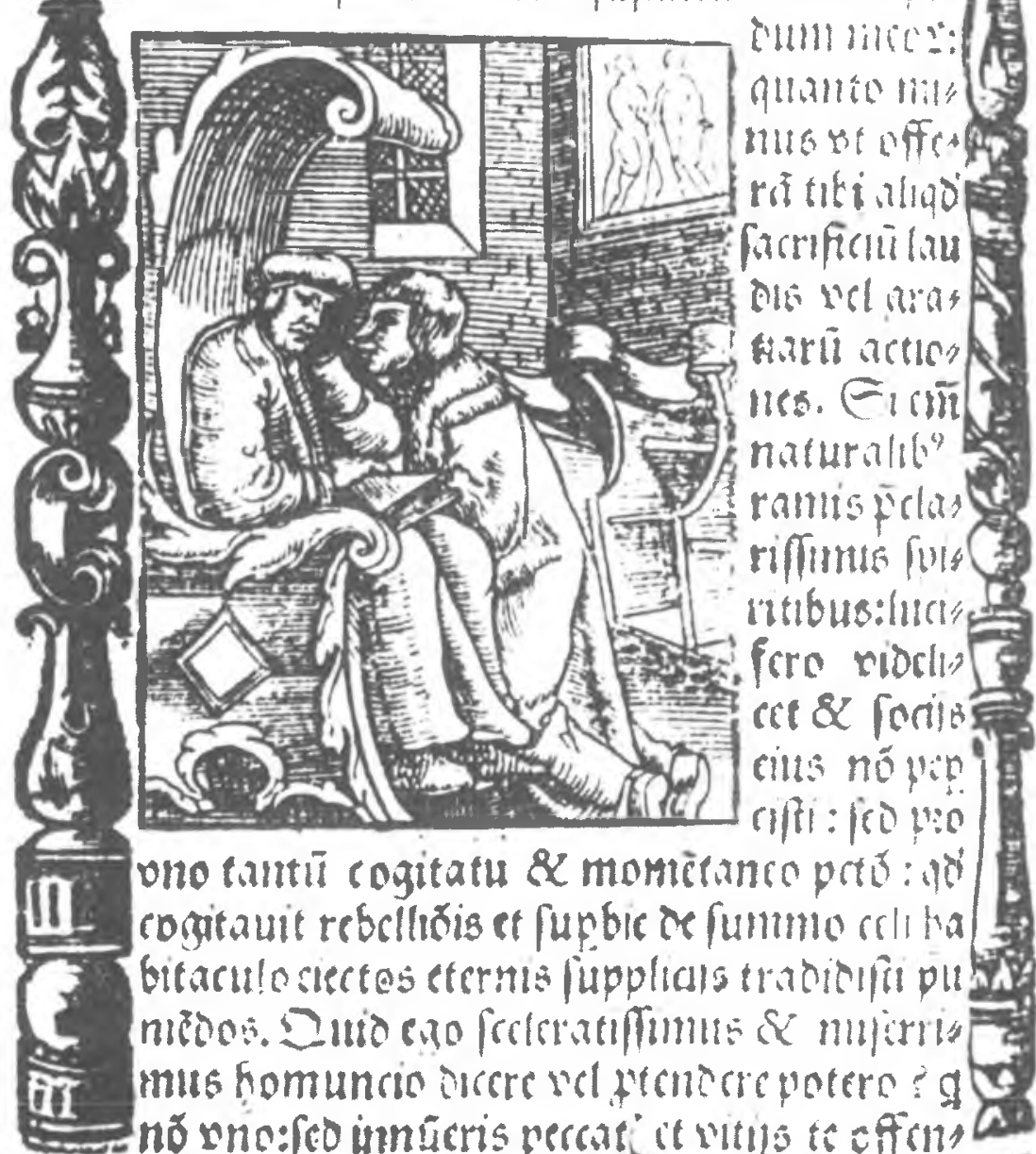

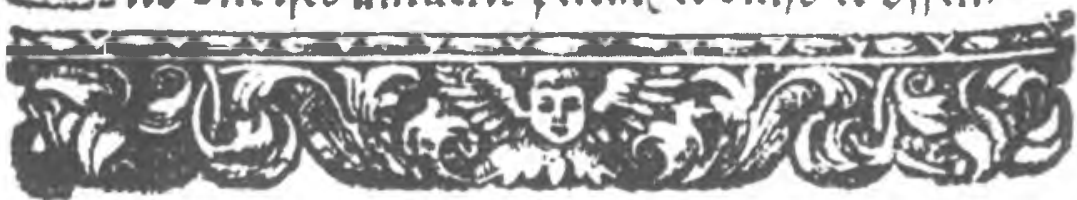

II. 2. 
jedno kolano przed Filipem de Valois, wkłada swoje złożone dłonie w jego (immixtio manuum) i wyraża wolę (volo) służenia ${ }^{19}$. W manuskrypcie francuskim z XIV w. (Paris, Bibliothèque Nationale, ms. lat. 960, fol. clxl), obok miniatury ukazującej penitenta, który podaje dłonie spowiednikowi, jest odnotowane "tunc peccato mittet manus suas in manibus sacerdotis et dicat..."20. Formuła stosowana w rycie sakramentu pokuty została wzięta z Ps. 30, 6 i koresponduje z modlitwą Chrystusa na krzyżu (Lk 23,46) „Ojcze w twoje ręce oddaje ducha mojego", wyrażająca całkowite zawierzenie siebie Bogu Ojcu.

Feudalne gesty, które miały miejsce w życiu świeckim, rzeczywiście mogły przeniknąc do liturgicznych ceremonii jeżeli w szczytowym okresie feudalizmu Kurii Rzymskiej od Innocentego III do Jana XXII, homagium składanego papieżom i tiary stawiającej papieży ponad wszystkimi ludźmi, oni sami chcieli widzieć siebie jako wasali Chrystusa i byli przedstawiani na obrazach w pozycji klęczącej, ze złożonymi dłońmi. Przy okazji konsekracji biskupiej kandydat wprawdzie nie składal homagium konsekrujacemu biskupowi, ale nie był zwolniony z przysięgi, że będzie strzegł depozytu wiary i będzie wierny Kościolowi oraz papieżowi, co było zwiazane z nawiedzeniem Stolicy Piotrowej po konsekracji. W rzymskim pontyfikale, który był częściowo zreformowany przez Innocentego III, znalazło się wskazanie, że biskup w czasie konsekracji powinien trzymać złożone świeżo namaszczone ręce, zanim papież nie poda mu pastorału. Podobnie zresztą przy święceniu kandydata na kapłana, powinien on trzymać złożone namaszczone ręce aż do czasu otrzymania pateny i kielicha ${ }^{21}$.

Zatem usprawiedliwionym wydaje się być wniosek, że w scenie sakramentu pokuty w Średniowieczu krzesło czy tron spowiednika, oraz postawa klęcząca i podawania dłoni przez penitenta, mająca swoje miejsce w homagium, z jednej strony oznaczają nie tylko zwykły mebel, ale miejsce zasiadania tego, który ma władzę i może sądzić i rozgrzeszać na mocy władzy kapłańskiej a $z$ drugiej strony postawę oddania, uniżenia i pokory przed Bogiem o czym świadczą postawa, gesty i slowa wypowiadane przez klęczącego penitenta w momencie podawania rąk spowiednikowi.

Strona „teatralna”, formalna, sakramentu pokuty ma odniesienie do stosunków społecznych panujących w ówczesnej Europie.

${ }^{19}$ A. Dawson Hedeman, Valois Legitimacy: Editorial Changes in Charles V's Grandes Chroniques de France. "The Art Bulletin", 66:1984, nr 1, s. 100-102, il. 1-3.

${ }^{20}$ A. Eljenholm Nicholas, op. cit., s. 223, przyp. 4.

${ }^{21}$ G. B. Ladner, Images and Ideas in the Middle Ages. Selected Studies in History and Art. T. 1. Storia e letteratura. Racolta di studi e testi 155. Roma 1983, s. 224-226. - Pozycja klęcząca związana była także z cnotą pokory. W XII w. „w drzewie cnót” pokora byla umieszczana u podstawy cnót jako, ,radix virtutum", patrz: M. Meiss, The Madonna of Humility. „The Art Bulletin", 18:1936, s. 456, 461. 